\title{
Advances in Electron Microscopy for Studying the Microorganism- mediated Reduction of Radionuclides in the Subsurface
}

\author{
Matthew J. Marshall, Alice C. Dohnalkova, David W. Kennedy, Andrew E. Plymale, \\ Bruce W. Arey, Alexander S. Beliaev, and James K. Fredrickson. Pacific Northwest \\ National Laboratory (PNNL), Richland, Washington 99354, USA
}

As a result of the Manhattan Project and the Cold War, it has been estimated that over 1 billion $\mathrm{m}^{3}$ of groundwater and $>75$ million $\mathrm{m}^{3}$ of soil have been contaminated with radionuclides in sites across the United States. In addition to direct disposal to soils, trenches, cribs, etc., large volumes of waste remain in storage at several Department of Energy (DOE) sites. Due to their long half-lives and relatively high environmental mobility, $U$ and $\mathrm{Tc}$ are the two primary risk-driving contaminants at these locations. In their most oxidized forms, U(VI) and Tc(VII) exhibit a high degree of environmental solubility, while they are considerably less soluble and precipitate as oxides at their lowest oxidation state, +4 . Under anoxic conditions, the bioreduction of U(VI) and $\mathrm{Tc}(\mathrm{VII})$ to insoluble oxides, $\mathrm{UO}_{2(\mathrm{~s})}$ (uraninite) and $\mathrm{TcO}_{2(\mathrm{~s})} \cdot \mathrm{nH}_{2} \mathrm{O}$, respectively, by dissimilatory metal-reducing bacteria (DMRB) can significantly alter the mobility of these radionuclides in contaminated groundwaters.

In our previous communications $[1,2]$, we have examined the biomolecular mechanisms of radionuclides transformation by DMRB. Using predictions based on genomic analysis and data obtained with gene deletion mutants, the redox-active proteins involved in the biotransformations of U(VI) and Tc(VII) have been well-characterized in one such DMRB, Shewanella oneidensis MR-1. In S. oneidensis MR-1, the redox-active proteins involved in these biotransformations are found associated with two sub-cellular locations: the periplasmic space $(\mathrm{P})$ and the cell outer membrane $(\mathrm{OM})$. In vivo kinetic studies with wild-type and mutant cells as well as in vitro assays using purified recombinant proteins have provided us with a better mechanistic understanding of U(VI) and Tc(VII) bioreduction process. Interestingly, these studies have repeatedly demonstrated the importance of electron microscopies for studying radionuclide biotransformations.

Works with Shewanella and other DMRB suggested that U(VI) reduction occurred in the cell periplasm, although extracellular uraninite nanoparticles were also noted. Using a combination of Electron Microcopy (EM), Synchrotron-based, micro X-ray fluorescence (XRF) imaging, and high-resolution immuno-EM, extracellular uraninite nanoparticles were investigated and found to be associated with a complex extracellular polymeric substance (ExPS) containing redox-active proteins that directly transfer electrons to $\mathrm{U}(\mathrm{VI})[1]$. Although the precise role of nanoparticulate $\mathrm{UO}_{2}$ interactions with ExPS remains unknown, it is possible that in the environment such association could influence the oxidation rate of $\mathrm{U}(\mathrm{IV})$ and/or the environmental mobility of nanoparticles in pore or groundwaters.

Similarly, Tc(VII) reduction by DMRB was generally considered to be catalyzed by a periplasmic hydrogenase. Reduction studies using $S$. oneidensis MR-1 mutants lacking all functional hydrogenases suggested that a second, novel Tc(VII) reductase pathway 
existed. Using high resolution-transmission EM (TEM) to visualize the sub-cellular localization of $\mathrm{Tc}$ in the hydrogenase-deficient mutant, $\mathrm{TcO}_{2}$ nanoparticles were localized only at the exterior face of the OM, suggesting that $\mathrm{Tc}(\mathrm{VII})$ reductases may also reside at that location [2]. Subsequent genetic and kinetic studies confirmed that OM cytochromes previously implicated in $\mathrm{Fe}, \mathrm{Mn}$, and $\mathrm{U}$ reduction may also play a role in $\mathrm{Tc}(\mathrm{VII})$ reduction by $S$. oneidensis MR-1.

The new insights into the radionuclide biotransformation processes provided by the EM technology/capability have enabled researchers to gain better understandings of how DMRB interact with these radionuclides in the environment. Newly isolated radionuclide-reducing bacteria (Fig 1) or those for which genetic manipulation techniques are unavailable [3] can now be visualized at high resolution to make informed hypothesis about molecular processes involved in the biotransformation processes. Studies using Cryo-EM to examine microbial associations in native, hydrated conditions will further provide exceptional unprecedented detail of biominerals associated with bacteria.

[1] Marshall, M.J. et al., PLoS Biol 4:e268 (2006). [2] Marshall, M.J. et al., Environ Microbiol 10:125-136 (2008). [3] Marshall, M.J. et al., Environ Microbiol 11:534-43 (2009).

This research was performed using the Environmental Molecular Sciences Laboratory (EMSL), a national scientific user facility sponsored by the DOE's Office of Biological and Environmental Research located at PNNL. Battelle Memorial Institute operates PNNL for the DOE under contract DE-AC05-76RL01830.
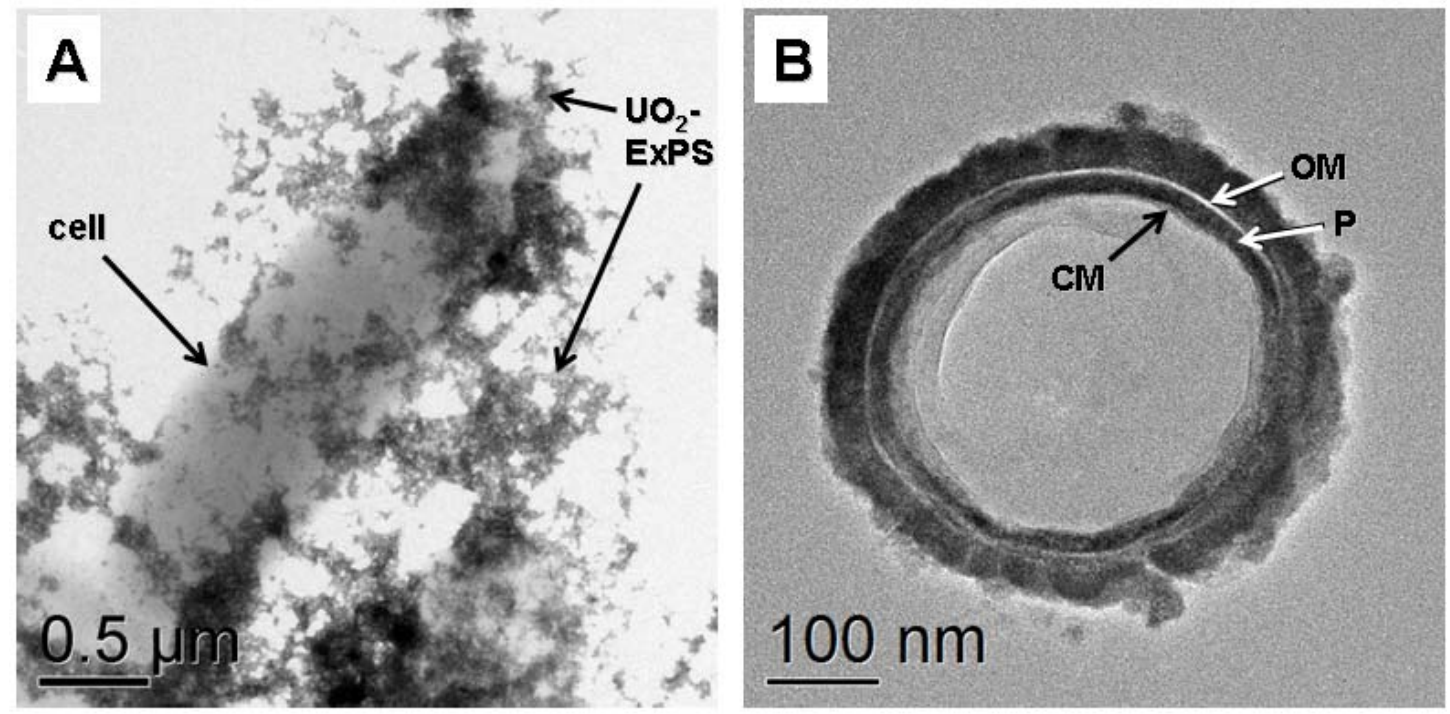

Fig 1. Electron microscopic localization of $\mathrm{UO}_{2}$ and $\mathrm{TcO}_{2}$ nanoparticles in newly isolated radionuclide-reducing bacteria. Unstained whole mount TEM micrograph of Shewanella sp. HRCR-7 incubated with U(VI) and lactate (A). The formation of extracellular $\mathrm{UO}_{2}$ nanoparticles with ExPS ( $\mathrm{UO}_{2}$-ExPS) is indicated by arrows. Unstained thin section TEM micrograph of Anaeromyxobacter dehalogenans 2CP-1 cell incubated with $\mathrm{Tc}(\mathrm{VII})$ and $\mathrm{H}_{2}(\mathrm{~B})$. Arrows indicate the cell membrane $(\mathrm{CM})$, periplasm $(\mathrm{P})$, and outer membrane $(\mathrm{OM})$. 